Review

\title{
Urgent global opportunities to prevent birth defects
}

\author{
Vijaya Kancherla ${ }^{a}$, Godfrey P. Oakley Jr. ${ }^{a, *}$, Robert L. Brent ${ }^{\mathrm{b}}$ \\ a Department of Epidemiology, Rollins School of Public Health, Emory University, Atlanta, GA, USA \\ ${ }^{\mathrm{b}}$ Alfred I. DuPont Hospital for Children, Jefferson Medical College, Wilmington, DE, USA
}

Keywords:

Birth defects

Congenital abnormalities

Population surveillance

Prevalence

Prevention

\begin{abstract}
S U M M A R Y
Birth defects are an urgent global health priority. They affect millions of births worldwide. But their prevalence and impact are largely under-ascertained, particularly in middle- and low-income countries. Fortunately, a large proportion of birth defects can be prevented. This review examines the global prevalence and primary prevention methods for major preventable birth defects: congenital rubella syndrome, folic acid-preventable spina bifida and anencephaly, fetal alcohol syndrome, Down syndrome, rhesus hemolytic disease of the fetus and the newborn; and those associated with maternal diabetes, and maternal exposure to valproic acid or iodine deficiency during pregnancy. Challenges to prevention efforts are reviewed. The aim of this review is to bring to the forefront the urgency of birth defects prevention, surveillance, and prenatal screening and counseling; and to help public health practitioners develop population-based birth defects surveillance and prevention programs, and policy-makers to develop and implement science-based public health policies.
\end{abstract}

(C) 2013 Published by Elsevier Ltd.

\section{Introduction}

Birth defects are one of the leading causes of infant mortality in the world, contributing to more than 3 million deaths among children aged $<5$ years [1]. Their impact is immeasurable, having life-long health and economic implications for the affected individual, the family, and society. Middle- and low-income countries have twice the prevalence and mortality associated with birth defects compared with developed countries [1]. When addressing mortality among people aged $<50$ years, birth defects are among top contributors.

A recent report on the global burden of disease ranked birth defects as the 17th most common cause of disability-adjusted lifeyears (DALYs), amounting to 39 million DALYs. This came as an improvement since 1990, when birth defects ranked 13th among the leading causes of DALYs and contributed to a total of 54 million DALYs [2]. These statistics indicate that birth defects prevention efforts in the last two decades were beneficial, and there is a need to further intensify their surveillance and prevention. Only then can we achieve maximum reduction in birth defects-associated DALYs in a global context. Also, there is an increasing consensus on shifting focus to non-communicable diseases worldwide, which are now leading the burden of disease and rising in prevalence.

\footnotetext{
* Corresponding author. Address: Department of Epidemiology, Rollins School of Public Health, Emory University, 1518 Clifton Rd NE, Room 4007, Atlanta, GA 30322 USA. Tel.: +1 678613 6918; fax: +1 4043256918 .

E-mail address: gpoakley@mindspring.com (G.P. Oakley).
}

Lack of population-based surveillance and prenatal care programs contributes to gaps in our knowledge of birth defects in the developing world. Even though they appear to be rare, birth defects are a major public health priority at a population level. As with polio and smallpox, many birth defects are preventable and can be completely eliminated by timely primary prevention.

We have reviewed current literature on a group of major birth defects that are highly preventable. These birth defects include congenital rubella syndrome, folic acid-preventable spina bifida and anencephaly, fetal alcohol syndrome, Down syndrome, and rhesus hemolytic disease of the fetus and newborn. We have also reviewed birth defects associated with maternal diabetes, those with in-utero exposures to valproic acid, and maternal iodine deficiency. Our aim is to identify their prevalence in the populations and challenges to primary prevention strategies. We hope that this review will serve as a resource to address modifiable risk factors for preventable birth defects and provide an update on current research in the field. Public health practitioners and epidemiologists can use this review as an update on population-based birth defects surveillance and prevention programs. Our review may be helpful to policy-makers to implement science-based policies such as mandatory food fortification, and universal prenatal screenings and vaccinations.

\section{Congenital rubella syndrome}

Congenital rubella syndrome is a group of birth defects that result from maternal infection to rubella virus during pregnancy. Affected infants suffer with cataracts, hearing loss, congenital heart defects, 
and both physical and mental retardation. Severity of these defects depends on the time at which the fetus is exposed to the infection in utero, with the highest risk during the first trimester. Congenital rubella syndrome also poses a high risk of transmission from the affected infant during the first year after their birth, contributing to the spread of infection to those in their household or close contact. First identified in 1941, congenital rubella syndrome has been associated with a high infant mortality worldwide [3]. Introduction of rubella vaccination during the early 1970s and effective implementation of mass vaccination programs in several World Health Organization (WHO) member countries in recent years has led to about $80 \%$ reduction in rubella cases, and consequently congenital rubella syndrome [4]. However, its prevention has not been complete due to challenges associated with birth and transmission rates in different countries [5]. Congenital rubella syndrome has been completely eliminated in the USA as of December 2011 [6], and an ongoing surveillance monitors the success of this program [7], whereas middleand low-income countries in Africa, the Western Pacific, and South East Asia, where the vaccination rates are below $70 \%$, have significantly high rates of rubella infections among women of childbearing age [8]. Because of these gaps in primary prevention, about 120000 rubella cases still occur each year in the world [4]. China, Bangladesh, Poland, Bosnia and Herzegovina, and Ukraine document the highest proportion of congenital rubella cases, with an estimated total of 100000 births affected each year [9]. Some of the challenges to total prevention of congenital rubella syndrome are variability in vaccination coverage within and between countries. Countries with high birth rate require more than $80 \%$ vaccine coverage among women of childbearing age, thus requiring additional vaccination campaigns. Also, population isolation in low-income countries hinders vaccination programs [5]. The WHO has strongly urged countries that are lacking rubella immunization programs to accelerate their efforts to prevent rubella and congenital rubella syndrome [10]. Complementing current immunization programs with selective rubella vaccination among girls and young women is recommended [3].

\section{Folic acid-preventable spina bifida and anencephaly}

Folic acid-preventable spina bifida and anencephaly (FAPSBA) are common birth defects affecting the central nervous system. In spite of unequivocal evidence from controlled trials in 1991 confirming the effectiveness of folic acid in prevention of spina bifida and anencephaly [11], each year about 246000 cases of FAPSBA occur globally [1]. Countries that have implemented mandatory folic acid fortification of food have seen a significant reduction in the prevalence of FAPSBA [12-14]. But not all countries implement mandatory fortification policies that promote adequate folic acid by women of reproductive age [15]. Bell and Oakley [16] have estimated the proportion of FAPSBA cases that can be prevented worldwide, suggesting that $75 \%$ of all neural tube defects can be prevented through folic acid fortification, and when there is a good coverage of population with access to the country-specific fortification program. Accordingly, less than one-quarter of total preventable cases of FAPSBA were prevented worldwide. The number of cases of FAPSBA prevented have increased from $9 \%$ in 2006 [16] to 15\% in 2012 [17]; however, more needs to be done to prevent remaining cases, which amount to 200000 cases each year globally. There is an urgent need for those countries with the majority of these cases, such as India [18] and China $[19,20]$, to implement mandatory folic acid fortification policies and to promote consumption among women of reproductive age. Some countries opt to offer folic acid supplements to adolescent girls and women, instead of fortifying centrally processed food. Such a prevention strategy based on folic acid supplement intake is shown to be effective in only $50 \%$ of women who adhere to the program [21]. It has also been shown that supplement programs for high-risk women with a history of neural tube defectaffected pregnancy, even if successful, prevent only a small fraction (2-5\%) of FAPSBA [21]. Thus, optimal prevention of FAPSBA is achievable only through mandatory fortification of centrally processed food. There are many challenges for mandatory fortification programs in low- and middle-income countries: fortification programs are known to be dynamic and influenced by industry and consumption patterns, lack of political will to implement mandatory fortification, resistance from the milling industry to purchase and disseminate folic acid premix in the flour, isolation and individual dietary practices of communities that limit intake of centrally processed flour, and concerns about safety, cost-effectiveness, and impact on consumer choice. In countries that implement fortification, compliance and uptake have to be monitored periodically. Overall, assessment of serum folate concentrations among women of reproductive age can serve as an easy and cost-effective way to identify risk for FAPSBA and implement primary prevention Figure 1.

\section{Fetal alcohol syndrome}

Fetal alcohol syndrome is a structural and neurodevelopmental group of disorders in individuals with prenatal exposure to alcohol. Those affected suffer lifelong disability, with no cure. There is a wide variation in the prevalence of fetal alcohol syndrome worldwide, and numbers of cases have steadily increased in the last decade [22]. In the USA, the estimated prevalence is 2-7 cases per 1000 live births [23]. Studies from Europe [24], Africa [25-27], Israel [28], Australia [29,30], and Russia [31] show a much higher prevalence. The highest prevalence to date has been reported from high-alcohol-consuming regions of South Africa (90 per 1000 births) [32]. The WHO has recently convened to study the burden of fetal alcohol syndrome in developing countries using in-school screeners. Worldwide, 5-10\% of all pregnancies are at risk for alcohol-related birth defects [33,34]. Recent studies in the USA show that almost $50 \%$ of reproductive-aged women used alcohol, which included about $8 \%$ of pregnant women; while binge drinking is prevalent in $15 \%$ of non-pregnant women and $1.4 \%$ of pregnant women [35]. Drinking during pregnancy is also a major concern in low- and middle-income countries [36-38]. As maternal alcohol use during pregnancy is frequently under-ascertained during the prenatal period, this estimate may be much higher in reality [39]. Behavioral modification among reproductive-aged women should be the central theme in the prevention of fetal alcohol syndrome [40]. Some challenges to prevention of fetal alcohol syndrome include cultural and societal attitudes concerning alcohol use, women with high-risk behaviors entering prenatal care late in pregnancy, and lack of, or inaccessible, preventive and counseling services in several countries. Addressing barriers such as guilt and embarrassment among women regarding their alcohol use will also be an important challenge in assessing the burden [41]. It has been shown that a majority of health care providers fail to address the effects of alcohol abuse or to diagnose fetal alcohol syndrome due to lack of training and knowledge [42,43]. Assessment of maternal alcohol use during pregnancy should become a standard and routine measure to aid in risk assessment for the fetus and for counseling and treatment of alcohol use. Finally, an integrated approach should be developed to provide health, social, and referral services in a culturally adopted setting to those affected with alcohol-related birth defects.

\section{Maternal age and Down syndrome}

Down syndrome is the most common chromosomal abnormality in newborns. Affected individuals have high rates of intellectual disability and several birth defects. Down syndrome was first characterized in the mid-1800s, and advanced maternal age was determined as the most significant risk factor in the early 1930s [44]. Non- 


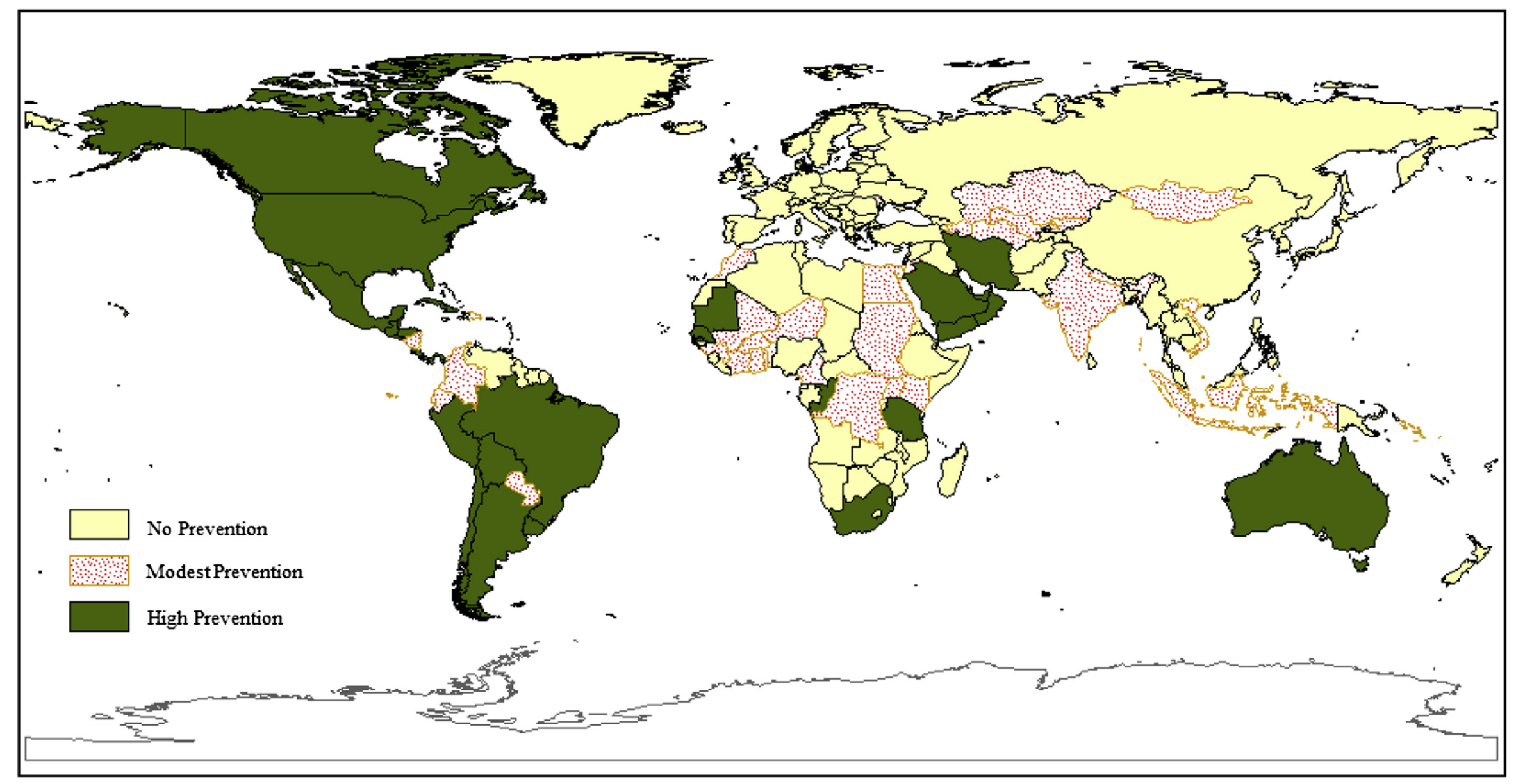

Figure 1. The status of global prevention of folic acid-preventable spina bifida and anencephaly, 2012 [17]. 
disjunction errors in chromosomes and/or biological aging of oocytes in mothers of advanced age are suggested as probable causes for Down syndrome [45]. Despite improved knowledge and screening, about 5400 births in the USA are affected with Down syndrome each year [45]. The prevalence of Down syndrome has increased in the last two decades, with an increasing trend in delaying childbirth globally [46]. Middle- and low-income countries record a large proportion of births to women of advanced age, while reporting twice as many cases of Down syndrome as developed countries [1,47]. On the contrary, countries where family planning is well-promoted show early and better-spaced pregnancies, and have lower births to women of advanced maternal age. European countries that have national screening policies for Down syndrome (within the first trimester) identify a large number of prenatally diagnosed Down syndrome cases, as compared to countries without such policies [48]. A large majority of prenatally diagnosed Down syndrome cases ( $~ 90 \%)$ are medically terminated. Socio-economic and technological disparities hinder the success of prenatal screening programs in both developed and developing countries. Both individual and societal changes that encourage lowering the age of conception among women will serve as the single most cost-efficient and effective intervention to prevent Down syndrome in future births. Implementation of universal screening and counseling (both pre and post conception) is urgently required in middle- and low-income countries. Improving organizational and cultural factors to reduce variation in prenatal screening will better contribute towards Down syndrome prevention in several countries [48].

\section{Rhesus hemolytic disease of the fetus and newborn}

Several red-cell antigens have been identified in association with the hemolytic disease of the fetus and the newborn (HDFN). Among these, antigen $\mathrm{RhD}$ is one of the most common. Incompatibility between RhD-negative mother and RhD-positive fetus during pregnancy will result in production of antibodies to the fetal $\mathrm{RhD}$ antigens (also termed as alloimmunization) [49]. Pregnancies complicated by alloimmunization have a high risk of fetal and neonatal morbidity and mortality in future pregnancies, and in the absence of timely prophylaxis can lead to fetal jaundice, hydrops (requiring intrauterine transfusions), fetal anemia, and stillbirths in about 2.4 per 1000 live births [50]. The mortality rate associated with HDFN in a developed country such as the UK is about 6 per 100000 live births or 50 deaths per year [51], and is expected to be much higher among developing countries. The alloimmunization is completely treatable by early identification and administering anti-D immune globulin to the expectant mother. Anti-D immune globulin has been in use since the 1960 s and has resulted in marked reduction in the alloimmunization to $\mathrm{RhD}$ antigen in pregnant women [52]. Lacking prophylaxis, it is estimated that at least one in every six RhD-negative women delivering an RhD-positive baby would be at risk [53]. To understand the racial distribution of this burden, $\sim 15 \%$ of Caucasians, $3-5 \%$ of African-Americans, $8 \%$ Asian-Indians, and $<1 \%$ of Asians have RhDnegative blood groups $[50,54,55]$. The prevalence of RhD-negative blood group in Europeans is relatively high, and varies between $11 \%$ and 21\%. For example, in western countries, as in England and Wales, it is estimated that $\sim 17 \%$ of the pregnant women are $\mathrm{RhD}$-negative, and, among these, 59\% are at risk for alloimmunization [56]. Non-invasive methods have gained prominence and have aided significantly in the reduction of the affected cases. However, several limitations exist. Improper screening for $\mathrm{RhD}$-negative status, limited prenatal care facilities, and failure of identification and treatment with immune globulin among high-risk pregnancies has contributed to persistence of the problem around the world. Developed countries have implemented successful screening programs to identify RhD-negative women early in pregnancy and administer the immune globulins to prevent HDFN; however, there is a wide variation in both screening methods and clinical management policies among different countries [57]. On the other hand, most developing countries lack screening. According to the March of Dimes, $100 \%$ of cases with HDFN can be prevented by immune prophylaxis [1]. In sub-Saharan Africa the frequency of RhD-negative women is: Nigeria $4.4 \%$, Guinea $4.1 \%$, Kenya $3.9 \%$, western Uganda 3.6\%, and Cameroon 2.4\%; yet there is limited prophylaxis available due to several challenges including poor research, limited access, affordability of anti-D immune globulin, high prevalence of illegal abortions, and poor documentation of medical histories on previous pregnancies, all of which are associated with high rates of HDFN-related morbidity and mortality in the region [5863]. In order to achieve reduction in the deaths associated with HDFN, there is an urgent need for prenatal screening for RhD antigens, universal access of immune prophylaxis to all women who test $\mathrm{RhD}$ negative, better documentation of reproductive histories, and promotion of post-partum prophylaxis to mothers at risk.

\section{Maternal diabetes associated birth defects}

Maternal insulin-dependent diabetes and adverse glycemic control in pregnancy has been consistently associated with a high risk of birth defects in the offspring both in developed and developing countries [1]. A three-fold increased risk has been noted for major cardiovascular, renal, and gastrointestinal defects in infants born to diabetic mothers compared with their counterparts [6466]. Overweight and obesity are significant predisposing factors that lead to diabetes, and both children and adults are at risk worldwide [67]. Despite advances in medical management, birth defects associated with maternal diabetes are a common occurrence. In the USA $\sim 100000$ babies are born to diabetic mothers. The prevalence estimates for diabetes-associated birth defects range between 2 and 6 per 1000 births in high-income countries, and are expected to be several times greater in low- and middleincome countries [1]. Pregnant mothers with higher levels of HbA1c at conception have a greater risk of delivering a baby with birth defects as compared to pregnant mothers with normal levels. Better glycemic control before pregnancy is shown to reduce the risk significantly [68]. Unfortunately, more than one-third of women of reproductive age with diabetes are unaware of their condition [69]; this proportion may be incrementally more in developing countries [70]. However, prevention of diabetesassociated birth defects is possible [71]. Selectively monitoring women with juvenile diabetes can be part of the solution. Also, screening women for high Gamma-hydroxybutyrate (GHb) concentration will help identify high-risk pregnancies, and prevention efforts can be focused accordingly [72]. Both public- and patientoriented approaches in lifestyle modification are needed. Awareness of diabetes and its pregnancy-related risk must be improved among women of reproductive age worldwide. Population-based screening for women with undiagnosed diabetes is also an urgent need. Challenges exist in terms of feasibility and funding for universal screening. Africa and South East Asia, which face the highest burden of diabetes, have a dearth of primary health centers that can provide oral hypoglycemic agents to pregnant diabetic women [73]. Other challenges include failure to adhere to, or respond to, treatment among those who are on diabetes medications [74]. A multipronged approach with increased awareness among health care professionals, periodic screening, and management, has been shown to have a positive impact on prevention $[75,76]$. As a primordial prevention, governments should devise health policies that promote both education and healthy lifestyles. Political will, advocacy by health care professionals, and involvement from the community are important next steps to boost prevention of diabetes-associated birth defects [74]. 


\section{Valproic acid}

A positive association between valproic acid (an anti-epileptic drug) taken in early pregnancy and having offspring with spina bifida was first shown in the year 1982 . This association was highly significant, with a 20 -fold increase in risk of spina bifida to babies born to mothers who were exposed to valproic acid in the first trimester compared with those born to mothers who were unexposed [77]. Several subsequent studies further confirmed this association, along with new findings of valproic acid teratogenicity in association with other major birth defects, including cardiac, urinary, and oro-facial defects in the fetus [77-84]. Following these studies, many countries have revised their prescription guidelines for women with epilepsy and have recommended judicious use of valproic acid during pregnancy for epilepsy disorders, advising less teratogenic forms of anti-epileptic drugs to women of childbearing age [85-88]. However, other uses of valproic acid, such as for pain, migraine, and bipolar disorder make them highly likely to stay in the market, and be prescribed to women of childbearing age without an epilepsy indication [89]. There is a high risk of off-label use of this drug in developing countries. The US Food and Drug Administration has made valproic acid a class $\mathrm{X}$ drug for migraines, where the risks involved in using valproic acid in pregnant women clearly outweigh potential benefits. Within the USA, it was estimated that $\sim 40$ cases of spina bifida have occurred due to valproic acid use [90], and about 4 per 1000 prescriptions are still written for valproic acid for nonepilepsy conditions [89]. The March of Dimes Global report on birth defects (2006) indicated that the risk of such exposure is even higher in developing countries where valproic acid use may be uncontrolled and more common compared with more expensive and less teratogenic anticonvulsive drugs [1,91]. Thus, it becomes an urgent necessity to educate not only neurologists, but psychiatrists and other practitioners to eliminate valproic acid prescriptions among women of childbearing age, and that its use is seldom justified, for both epilepsy and non-epilepsy indications. Additionally, awareness needs to be brought both among the medical community and among the population about the teratogenic effects of this drug, so women in developing countries are not exposed to valproic acid.

\section{Iodine deficiency}

Iodine deficiency affects $\sim 2$ billion people globally and is a large concern for women of childbearing age. Each year, about 50 million children are born to iodine-deficient mothers, and about $40 \%$ of these children suffer significant intellectual disability [92]. In 2007, the WHO reported a high prevalence of iodine deficiency in both developed and developing regions of the world, and not just confined to remote and mountainous regions, as previously thought [93]. National nutritional surveys from the USA estimate that $\sim 35 \%$ of pregnant women have at least mild iodine deficiency [94]. To address this problem, the American Thyroid Association recommends $150 \mu \mathrm{g}$ per day of iodine intake for pregnant and lactating women, starting early at preconception $[95,96]$. Pregnancy confers an increased need for iodine, [97] and its insufficiency has been associated with cretinism, intellectual delays, birth defects, and other suboptimal outcomes in the infant $[95,98]$. Iodine deficiency is also the most important cause of preventable intellectual disability in infants worldwide [96]. Dietary intake is the only source of iodine; however, prenatal vitamins and supplements also contain iodine and should be recommended to women of childbearing age. Use of iodized salt has been implemented in several countries to reduce iodine deficiency. But only $70 \%$ of households worldwide have access to iodized salt, and there is a need to promote it extensively to achieve optimal intake [99]. Known challenges to successful iodization include use of cheaper non-iodized salt, limitation in quality control during salt production, compliance failures, personal preferences, lack of awareness by households about benefits of iodized salt, market fluctuations, and poor enforcement of regulations mandating iodization [92]. Political commitment and salt iodization legislation are also important to move ahead. There is a need to identify optimal indicators for iodine deficiency, improved screening of women of childbearing age, and monitoring iodine content in salt. As most people are limiting their salt intake to reduce their risk of hypertension, other vehicles have to be explored to deliver needed iodine to populations worldwide [92]. Taking these timely steps, we may be able to prevent a majority of babies from the ill outcomes associated with iodine deficiency.

\section{Other opportunities for prevention}

A recent review summarized a list of preventable birth defects (Box 1) [100]. This prevention can be achieved by screening for chromosome abnormalities and genetic disease, vaccinations, screening for teratogenic infectious diseases such as human immunodeficiency virus and gonorrhea, and limiting or eliminating the use of all known teratogenic drugs (e.g. anticoagulants, retinoids, and thalidomide). We should also be vigilant of new teratogens. Parents should be informed of preconception diagnostic choices including amniocentesis, chorionic villous sampling, maternal serum monitoring, and ultrasound monitoring to diagnose identifiable genetic diseases and serious birth defects.

Box 1

Prevention of congenital malformation and reproductive effect [100].

1. Rubella vaccination.

2. Folic acid and vitamin $B_{12}$ supplementation: $400 \mu \mathrm{g}$ and $6 \mu \mathrm{g}$ per day.

3. Supplementation of iodide to deficient patients and populations.

4. Meticulous diabetic control.

5. Competent diagnosis and management of maternal hypothyroidism.

6. Screening for chromosome abnormalities and genetic disease.

7. Hepatitis B vaccination for at-risk women.

8. Human immunodeficiency virus screening and treatment.

9. Screening for Neisseria gonorrhoea, Chlamydia trachomatis, group B streptococcus.

10. Vaccination of patients with group B streptococcus.

11. Maternal phenylalanine management for maternal phenylketonurics.

12. Management or discontinuation of oral use of anticoagulants, anticonvulsants, retinoids, thalidomide and all known teratogens.

13. Recognize that new teratogens can be represented in the next new drug or chemical exposure: angiotensinconverting enzyme inhibitors, angiotensin II receptor blockers, mycophenolate, tumor necrosis factor blockers.

14. Amniocentesis, chorionic villus sampling, maternal serum monitoring, ultrasound monitoring to diagnose identifiable genetic diseases and serious birth defects in order for the parents to be informed about their options.

15. Maternal smoking and alcohol cessation.

16. Obesity control in itself reduces the risk of birth defects and decreases the risk of developing diabetes.

17. Immunization against known teratogenic infections. Botulina toxin vaccine for the pregnant mother to prevent infant botulism.

18. Malaria vaccine to prevent malaria in pregnancy which increases the risk of miscarriage. 
Timely counseling on high-risk behavioral and lifestyle choices such as maternal smoking, alcohol, caffeine, recreational drugs, and obesity and overweight is needed in relation to their adverse effects on pregnancy. While there are many prevention strategies to reduce the incidence of birth defects worldwide, there is not enough space allotted in this article for such extensive review.

\section{Conclusion}

Opportunities to prevent birth defects are abundant, but there are also many challenges in the process. Pediatricians, researchers, and public health practitioners in the field of birth defects should intensify prevention efforts, and undertake comprehensive and integrated efforts to accelerate the pace of prevention at a global scale for preventable birth defects. Help and commitment from governmental and non-governmental organizations, in a complementary manner, is crucial to developing affordable and feasible prevention programs. Only then can we achieve our goal of bringing current rates of major preventable birth defects close to nil.

We have witnessed the global eradication of polio, which is almost of the same magnitude as the current number of cases of folic acid-preventable spina bifida. Similarly, an integrated approach from the government and non-governmental agencies has resulted in global eradication of smallpox. Lessons from successful programs can be shared. Birth defects prevention is achievable by combating socio-economic inequities and disparities in health care for women of reproductive age. Need-driven and impact-oriented approaches with improved education, prophylaxis, and prenatal care are needed. There exists an urgent need to translate research findings to policy.

Now that developed countries are on their path towards success, priority should now be placed on middle- and low-income countries. Funding for birth defects surveillance is urgently required to plan and develop a functional primary prevention infrastructure for future births. Over time, the health and economic returns, both at micro and macro levels, would be significant. Political will and commitment by communities are an absolute necessity to initiate and sustain birth defects prevention on a global scale.

\section{Practice points}

- Global programs to prevent birth defects are an urgent global health priority.

- Congenital rubella syndrome and folic acid-preventable spina bifida and anencephaly could be eliminated from all countries by implementing prevention programs already shown to eliminate these birth defects in a few countries.

- Effective intervention programs must be developed and implemented to prevent the three-fold increase in major malformations among women with insulin-dependent diabetes mellitus, as well as birth defects and developmental disorders from in-utero exposure to alcohol.

- Valproic acid should be limited to persons with epilepsy who have been shown not to have control with at least one other anticonvulsant, and should never be the first-line treatment for epilepsy for women of reproductive age.

- Active, effective intervention programs promoting optimal maternal birth age are needed to reduce the current Down syndrome epidemic in developed countries and to prevent the epidemic in countries that have yet to experience it.

- There is a need to further intensify birth defects surveillance and prevention programs in developing countries.

- Political will and commitment by communities are integral for birth defects prevention on a global scale.

\section{Conflict of interest statement}

None declared.

\section{Funding sources}

None.

\section{References}

*[1] Christianson A, Howson CP, Modell B. Global report on birth defects. White Plains, NY: March of Dimes; 2006.

[2] Murray CJ, Lopez AD. Measuring the global burden of disease. N Engl J Med 2013;369:448-57.

*[3] World Health Organization. Global measles and rubella strategic plan: 2012-2020 http://www.who.int/immunization/newsroom/Measles Rubella_StrategicPlan_2012_2020.pdf.

[4] US Centers for Disease Control and Prevention. Progress toward control of rubella and prevention of congenital rubella syndrome - worldwide, 2009. Morb Mortal Wkly Rep 2010;59:1307-10.

[5] Metcalf CJ, Lessler J, Klepac P, Cutts F, Grenfell BT. Impact of birth rate seasonality and transmission rate on minimum levels of coverage needed for rubella vaccination. Epidemiol Infect 2012;140:2290-301.

[6] US Centers for Disease Control and Prevention. Documentation and verification of measles, rubella and congenital rubella syndrome elimination in the region of the Americas. United States National Report. Atlanta: CDC; 2012.

[7] Reef SE, Redd SB, Abernathy E, Kutty P, Icenogle JP. Evidence used to support the achievement and maintenance of elimination of rubella and congenital rubella syndrome in the United States. J Infect Dis 2011;204: S593-7.

[8] Cutts FT, Vynnycky E. Modelling the incidence of congenital rubella syndrome in developing countries. Int J Epidemiol 1999;28:1176-84.

[9] World Health Organization. Immunization, vaccines and biologicals rubella. Geneva: WHO; 2012. http://www.who.int/immunization/topics/ rubella/en/index.html.

[10] World Health Organization. Rubella vaccines: WHO position paper. Wkly Epidemiol Rec 2011;86:301-16.

[11] Medical Research Council. Prevention of neural tube defects: results of the Medical Research Council Vitamin Study. MRC Vitamin Study Research Group. Lancet 1991;338:131-7.

[12] Honein MA, Paulozzi LJ, Mathews TJ, Ericson JD, Wong LY. Impact of folic acid fortification of the US food supply on the occurrence of neural tube defects. JAMA 2001;285:2981-6.

[13] De Wals P, Tairou F, Van Allen MI, Uh SH, Lowry RB, Sibbald B, et al Reduction in neural-tube defects after folic acid fortification in Canada. N Engl J Med 2007:357:135-42.

[14] Hertrampf E, Cortes F, Erickson JD, Cayazzo M, Freire W, Bailey LB, et al. Consumption of folic acid-fortified bread improves folate status in women of reproductive age in Chile. J Nutr 2003;133:3166-9.

[15] Evans SE, Mygind VL, Peddie MC, Miller JC, Houghton LA Effect of increasing voluntary folic acid food fortification on dietary folate intakes and adequacy of reproductive-age women in New Zealand. Public Health Nutr 2013 Jul 9:1-7 [Epub ahead of print].

*[16] Bell KN, Oakley Jr GP. Tracking the prevention of folic acid-preventable spina bifida and anencephaly. Birth Defects Res A Clin Mol Teratol 2006;76:654-7.

[17] Youngblood ME, Williamson R, Bell KN, Johnson O Kancherla V, Oakley Jr GP. 2012 update on global prevention of folic acid-preventable spina bifida and anencephaly. Birth Defects Res A Clin Mol Teratol 2013;97:658-63.

[18] Bhide P, Sagoo GS, Moorthie S, Burton H, Kar A. Systematic review of birth prevalence of neural tube defects in India. Birth Defects Res A Clin Mol Teratol 2013;97:437-43.

[19] Zhu J, Li X, Wang Y, Mu D, Dai L, Zhou G, et al. Prevalence of neural tube defect pregnancies in China and the impact of gestational age of the births from 2006 to 2008: a hospital-based study. J Matern Fetal Neonatal Med 2012;25:1730-4.

[20] Zhang L, Ren A, Li Z, Hao L, Tian Y, Li Z. Folate concentrations and folic acid supplementation among women in their first trimester of pregnancy in a rural area with a high prevalence of neural tube defects in Shanxi, China. Birth Defects Res A Clin Mol Teratol 2006:76:461-6.

*[21] Oakley Jr GP. Elimination of folic acid-preventable neural tube defects. Am J Prev Med 2008;35:606-7.

[22] May PA, Gossage JP. Estimating the prevalence of fetal alcohol syndrome. A summary. Alcohol Res Health 2001:25:159-67.

[23] May PA, Gossage JP, Kalberg WO, Robinson LK, Buckley D, Manning M et al. Prevalence and epidemiologic characteristics of FASD from various research methods with an emphasis on recent in-school studies. Dev Disabil Res Rev 2009;15:176-92.

[24] May PA, Fiorentino D, Coriale G, Kalberg WO, Hoyme HE, Aragon AS, et al. Prevalence of children with severe fetal alcohol spectrum disorders in 
communities near Rome, Italy: new estimated rates are higher than previous estimates. Int I Environ Res Public Health 2011;8:2331-51.

[25] Olivier L, Urban M, Chersich M, Temmerman M, Viljoen D. Burden of fetal alcohol syndrome in a rural West Coast area of South Africa. S Afr Med J 2013; 103:402-5.

[26] Viljoen DL, Gossage JP, Brooke L, Adnams CM, Jones KL, Robinson LK, et al. Fetal alcohol syndrome epidemiology in a South African community: a second study of a very high prevalence area. J Stud Alcohol 2005;66:593604.

[27] Urban M, Chersich MF, Fourie LA, Chetty C, Olivier L, Viljoen D. Fetal alcohol syndrome among grade 1 schoolchildren in Northern Cape Province: prevalence and risk factors. S Afr Med J 2008;98:877-82.

[28] Tenenbaum A, Hertz P, Dor T, Castiel Y, Sapir A, Wexler ID. Fetal alcohol spectrum disorder in Israel: increased prevalence in an at-risk population. Isr Med Assoc J 2011;13:725-9.

[29] Elliott EJ, Payne J, Morris A, Haan E, Bower C. Fetal alcohol syndrome: a prospective national surveillance study. Arch Dis Child 2008;93:732-7.

[30] Burns L, Breen C, Bower C, O'Leary C, Elliott EJ. Counting fetal alcohol spectrum disorder in Australia: the evidence and the challenges. Drug Alcohol Rev 2013;32:461-7.

[31] Balachova T, Bonner B, Chaffin M, Bard D, Isurina G, Tsvetkova L, et al. Women's alcohol consumption and risk for alcohol-exposed pregnancies in Russia. Addiction 2012;107:109-17.

[32] May PA, Gossage JP, Marais AS, Adnams CM, Hoyme HE, Jones KL, et al. The epidemiology of fetal alcohol syndrome and partial FAS in a South African community. Drug Alcohol Depend 2007;88:259-71.

*[33] Ramsay M. Genetic and epigenetic insights into fetal alcohol spectrum disorders. Genome Med 2010;2:27.

[34] Abel EL. An update on incidence of FAS: FAS is not an equal opportunity birth defect. Neurotoxicol Teratol 1995:17:437-43.

[35] US Centers for Disease Control and Prevention. Alcohol use and binge drinking among women of childbearing age - United States, 2006-2010. Morb Mortal Wkly Rep 2012;61:534-8.

[36] Rosenthal J, Christianson A, Cordero J. Fetal alcohol syndrome prevention in South Africa and other low-resource countries. Am J Public Health 2005;95:1099-101.

[37] Williams AD, Nkombo Y, Nkodia G, Leonardson G, Burd L. Prenatal alcohol exposure in the Republic of the Congo: prevalence and screening strategies. Birth Defects Res A Clin Mol Teratol 2013;97:489-96.

[38] Kim O, Park K. Prenatal alcohol consumption and knowledge about alcohol consumption and fetal alcohol syndrome in Korean women. Nurs Health Sci 2011;13:303-8.

[39] Stoler JM, Holmes LB. Under-recognition of prenatal alcohol effects in infants of known alcohol abusing women. J Pediatr 1999;135:430-6.

[40] de Sanctis L, Memo L, Pichini S, Tarani L, Vagnarelli F. Fetal alcohol syndrome: new perspectives for an ancient and underestimated problem. J Matern Fetal Neonatal Med 2011:24:34-7.

[41] Zelner I, Shor S, Lynn H, Roukema H, Lum L, Eisinga K, et al. Neonatal screening for prenatal alcohol exposure: assessment of voluntary maternal participation in an open meconium screening program. Alcohol 2012;46:269-76.

[42] Tough S, Clarke M, Cook J. Fetal alcohol spectrum disorder prevention approaches among Canadian physicians by proportion of Native/Aboriginal patients: practices during the preconception and prenatal periods. Matern Child Health J 2007;11:385-93.

[43] Payne JM, France KE, Henley N, D’Antoine HA, Bartu AE, O'Leary CM, et al. RE-AIM evaluation of the Alcohol and Pregnancy Project: educational resources to inform health professionals about prenatal alcohol exposure and fetal alcohol spectrum disorder. Eval Health Prof 2011;34:57-80.

[44] Penrose LS. The relative effects of paternal and maternal age in Mongolism. J Genet 1933;27:219-24.

*[45] Sherman SL, Allen EG, Bean LH, Freeman SB. Epidemiology of Down syndrome. Ment Retard Dev Disabil Res Rev 2007;13:221-7.

[46] Shin M, Bessler LM, Kucik JE, Lu C, Siffel C, Correa A. Prevalence of Down syndrome among children and adolescents in 10 regions of the United States. Pediatrics 2009;124:1565-71.

[47] Watcham SJ, Schon S, Christianson AL. Neglect in the care of pregnant South African women of advanced maternal age. S Afr Med J 2007;97(1064):1068-9.

[48] Boyd PA, Devigan C, Khoshnood B, Loane M, Garne E, Dolk H, et al. Survey of prenatal screening policies in Europe for structural malformations and chromosome anomalies, and their impact on detection and termination rates for neural tube defects and Down's syndrome. Br J Obstet Gynaecol 2008;115:689-96.

[49] Moise KJ. Fetal anemia due to non-Rhesus-D red-cell alloimmunization. Semin Fetal Neonatal Med 2008:13:207-14.

[50] van der Schoot CE, Hahn S, Chitty LS. Non-invasive prenatal diagnosis and determination of fetal Rh status. Semin Fetal Neonatal Med 2008;13:63-8.

[51] Whitfield CR, Raafat A, Urbaniak SJ. Underreporting of mortality from RhD haemolytic disease in Scotland and its implications: retrospective review. BMJ 1997;315:1504-5.

[52] Clarke C, Hussey RM. Decline in deaths from rhesus haemolytic disease of the newborn. J R Coll Physicians Lond 1994;28:310-1.

[53] Greenough A. The role of immunoglobulins in neonatal Rhesus haemolytic disease. BioDrugs 2001;15:533-41.
[54] Lee CK, Ma ES, Tang M, Lam CC, Lin CK, Chan LC. Prevalence and specificity of clinically significant red cell alloantibodies in Chinese women during pregnancy - a review of cases from 1997 to 2001. Transfus Med 2003;13: 227-31.

[55] Narang A, Jain N. Haemolytic disease of newborn. Indian J Pediatr 2001;68:167-72.

*[56] National Institute of Clinical Excellence. Technology appraisal guidance 41. Guidance on the use of routine antenatal anti-D prophylaxis for RHDnegative women. London: NICE; 2002.

[57] Bettelheim D, Penzer S, Reesink HW, Csapo B, Pessoa C, Guerra F, et al. Monitoring and treatment of anti-D in pregnancy. Vox Sang 2010;99:17792.

[58] Osaro E, Charles AT. Rh isoimmunization in Sub-Saharan Africa indicates need for universal access to anti-RhD immunoglobulin and effective management of D-negative pregnancies. Int J Women's Health 2010;2: 429-37.

[59] Natukunda B, Mugyenyi G, Brand A, Schonewille H. Maternal red blood cell alloimmunisation in south western Uganda. Transfus Med 2011;21:262-6.

[60] Mwangi J. Blood group distribution in an urban population of patient targeted blood donors. East Afr Med J 1999;76:615-8.

[61] Jeremiah ZA. An assessment of the clinical utility of routine antenatal screening of pregnant women at first clinic attendance for haemoglobin genotypes, haematocrit, $\mathrm{ABO}$ and Rh blood groups in Port Harcourt, Nigeria. Afr J Reprod Health 2005;9:112-7.

[62] Loua A, Lamah MR, Haba NY, Camara M. Frequency of blood groups ABO and rhesus D in the Guinean population. Transfus Clin Biol 2007;14:435-9.

[63] Tagny CT, Fongue VF, Mbanya D. The erythrocyte phenotype in ABO and Rh blood groups in blood donors and blood recipients in a hospital setting of Cameroon: adapting supply to demand. Rev Med Brux 2009;30:159-62.

[64] Eidem I, Stene LC, Henriksen T, Hanssen KF, Vangen S, Vollset SE, et al. Congenital anomalies in newborns of women with type 1 diabetes: nationwide population-based study in Norway, 1999-2004. Acta Obstet Gynecol Scand 2010;89:1403-11.

[65] Persson M, Norman M, Hanson U. Obstetric and perinatal outcomes in type 1 diabetic pregnancies: a large, population-based study. Diabetes Care 2009;32:2005-9.

[66] Macintosh MC, Fleming KM, Bailey JA, Doyle P, Modder J, Acolet D, et al. Perinatal mortality and congenital anomalies in babies of women with type 1 or type 2 diabetes in England, Wales, and Northern Ireland: population based study. BMJ 2006;333:177.

[67] Dietz WH. Overweight in childhood and adolescence. N Engl J Med 2004;350:855-7.

[68] Wong VW, Suwandarathne H, Russell H. Women with pre-existing diabetes under the care of diabetes specialist prior to pregnancy: are their outcomes better? Aust NZ J Obstet Gynaecol 2013;53:207-10.

[69] Correa A, Gilboa SM, Botto LD, Moore CA, Hobbs CA, Cleves MA, et al. Lack of periconceptional vitamins or supplements that contain folic acid and diabetes mellitus-associated birth defects. Am J Obstet Gynecol 2012;206(218):e1-13.

[70] Mbanya JC, Motala AA, Sobnqwi E, Assah FK, Enoru ST. Diabetes in subSaharan Africa. Lancet 2010;375:2254-66.

[71] Oakley Jr GP. Failing to prevent birth defects caused by maternal diabetes mellitus. Am J Obstet Gynecol 2012;206:179-80.

[72] Guerin A, Nisenbaum R, Ray JG. Use of maternal GHb concentration to estimate the risk of congenital anomalies in the offspring of women with prepregnancy diabetes. Diabetes Care 2007;30:1920-5.

*[73] Mohan V, Seedat YK, Pradeepa R. The rising burden of diabetes and hypertension in southeast Asian and African regions: need for effective strategies for prevention and control in primary health care settings. Int J Hypertens 2013;2013:409083.

[74] Bergman M. Inadequacies of current approaches to prediabetes and diabetes prevention. Endocrine 2013;44:623-33.

[75] Dim CC, Okafor C, Ikeme AC, Anyahie BU. Diabetes mellitus in pregnancy: an update on the current classification and management. Niger J Med 2012;21:371-6.

*[76] Ali S, Dornhorst A. Diabetes in pregnancy: health risks and management. Postgrad Med J 2011;87:417-27.

[77] Bjerkedal T, Czeizel A, Goujard J, Kallen B, Mastroiacova P, Nevin N, et al Valproic acid and spina bifida. Lancet 1982;2:1096.

[78] Wyszynski DF, Nambisan M, Surve T, Alsdorf RM, Smith CR, Holmes LB, et al. Increased rate of major malformations in offspring exposed to valproate during pregnancy. Neurology 2005;64:961-5.

[79] Morrow J, Russell A, Guthrie E, Parsons L, Robertson I, Waddell R, et al. Malformation risks of antiepileptic drugs in pregnancy: a prospective study from the UK Epilepsy and Pregnancy Register. J Neurol Neurosurg Psychiatry 2006;77:193-8.

[80] Artama M, Auvinen A, Raudaskoski T, Isojärvi I, Isojärvi J. Antiepileptic drug use of women with epilepsy and congenital malformations in offspring. Neurology 2005;64:1874-8.

[81] Kaaja E, Kaaja R, Hiilesmaa V. Major malformations in offspring of women with epilepsy. Neurology 2003;60:575-9.

[82] Kaneko S, Battino D, Andermann E, Wada K, Kan R, Takeda A, et al. Congenital malformations due to antiepileptic drugs. Epilepsy Res 1999;33:145-58. 
[83] Vajda F, O’Brien T. Valproic acid use in pregnancy and congenital malformations. N Engl J Med 2010;363:1771.

[84] Werler MM, Ahrens KA, Bosco JL, Mitchell AA, Anderka MT, Gilboa SM, et al. Use of antiepileptic medications in pregnancy in relation to risks of birth defects. Ann Epidemiol 2011;21:842-50.

[85] Harden CL, Meador KJ, Pennell PB, Hauser WA, Gronseth GS, French JA, et al. Management issues for women with epilepsy -focus on pregnancy (an evidence-based review): II. Teratogenesis and perinatal outcomes: report of the Quality Standards Subcommittee and Therapeutics and Technology Subcommittee of the American Academy of Neurology and the American Epilepsy Society. Epilepsia 2009;50:1237-46.

[86] Vajda FJ, Horgan D, Hollinworth S, Graham J, Hitchcock AA, Roten A, et al. The prescribing of antiepileptic drugs for pregnant Australian women. Aust NZ J Obstet Gynaecol 2012;52:49-53.

[87] Glauser T, Ben-Menachem E, Bourgeois B, Cnaan A, Chadwick D, Guerreiro C, et al. ILAE treatment guidelines: evidence-based analysis of antiepileptic drug efficacy and effectiveness as initial monotherapy for epileptic seizures and syndromes. Epilepsia 2006;47:1094-120.

[88] Savica R, Beghi E, Mazzaglia G, Innocenti F, Brignoli O, Cricelli C, et al. Prescribing patterns of antiepileptic drugs in Italy: a nationwide populationbased study in the years 2000-2005. Eur J Neurol 2007; 14:1317-21.

*[89] Adedinsewo DA, Thurman DJ, Luo YH, Williamson RS, Odewole OA, Oakley Jr GP. Valproate prescriptions for nonepilepsy disorders in reproductive-age women. Birth Defects Res A Clin Mol Teratol 2013;97: $403-8$

[90] Gilboa SM, Broussard CS, Devine OJ, Duwe KN, Flak KL, Boulet SL, et al. Influencing clinical practice regarding the use of antiepileptic medications during pregnancy: modeling the potential impact on the prevalences of spina bifida and cleft palate in the United States. Am J Med Genet C Semin Med Genet 2011;157:234-46.

[91] Shorvon SD, Farmer PJ. Epilepsy in developing countries: a review of epidemiological, sociocultural, and treatment aspects. Epilepsia 1988;29: S36-54.

[92] Padilla CD, Fagela-Domingo C. Eliminating iodine deficiency: obstacles and their removal. Ann Acad Med Singapore 2008;37:45-54.

[93] Li M, Eastman CJ. The changing epidemiology of iodine deficiency. Nat Rev Endocrinol 2012;8:434-40.

[94] Caldwell KL, Makhmudov A, Ely E, Jones RL, Wang RY. Iodine status of the U.S. population, National Health and Nutrition Examination Survey, 2005-2006 and 2007-2008. Thyroid 2011;21:419-27.

[95] Obican SG, Jahnke GD, Soldin OP, Scialli AR. Teratology Public Affairs Committee position paper: iodine deficiency in pregnancy. Birth Defects Res A Clin Mol Teratol 2012;94:677-82.

[96] Leung AM, Pearce EN, Braveman LE. Sufficient iodine intake during pregnancy: just do it. Thyroid 2013;23:7-8.

[97] de Escobar GM, Obregon MJ, del Rey FE. Iodine deficiency and brain development in the first half of pregnancy. Public Health Nutr 2007:10: 1554-70.

98] Pearce EN. Effects of iodine deficiency in pregnancy. J Trace Elem Med Biol $2012 ; 26: 131-3$

[99] Zimmerman MB, Andersson M. Update on iodine status worldwide. Curr Opin Endocrinol Diabetes Obes 2012;19:382-7.

[100] Brent RL. The role of the pediatrician in preventing congenital malformations. Pediatr Rev 2011;32:411. 